\title{
Teaching medical ethics: University of Edinburgh
}

Kenneth Boyd, Colin Currie, Ian Thompson, Alison J. Tierney Edinburgh Medical Group Research Project in Medical Ethics and Education, University of Edinburgh, Edinburgh

The Edinburgh Medical Group Research Project is unique in Britain. Part of its function is to experiment with teaching medical ethics both inside and outside of the Medical School. The papers which follow have been written by two full-time reseach fellows working with the Project and two of the professional advisers, one nursing and one medical. Together they give a picture of the wide scope of exerimental teaching taking place in Edinburgh and present some preliminary results from these experiments.

\section{Experimental curriculum-related teaching of medical ethics}

Traditionally the main formal provision for medical ethics teaching in the Edinburgh Medical School is in six hours of lectures and discussions in the Forensic Medicine course, and in a number of informal seminars in the Department of Therapeutics. However, in the past two years this teaching has been supplemented by a number of attempts to integrate the teaching of medical ethics into ordinary academic and clinical teaching within the the Medical School. These innovative experiments have been associated with the setting up of the Edinburgh Medical Group Research Project in Medical Ethics and Education.

Part of the EMG Research Project's remit was to explore the feasibility of integrated and multidisciplinary teaching of medical ethics. Obviously the two full-time research fellows and the part-time medical and nursing advisers had no authority to implement immediately these proposals. Authority had to be sought and co-operation elicited from Heads of Departments in the Medical School. To assist in this task an inter-disciplinary, staff/student advisory committee was set up. This committee, under the chairmanship of the Professor of Forensic Medicine, undertook preliminary surveys of attitudes of staff and students in the Medical School to the teaching of medical ethics; and it became obvious that there was overwhelming support for the following views:

I) That insufficient time is devoted to the examination of social, moral and legal issues raised by the practice of medicine;

2) That so far as possible medical ethics teaching should be integrated into ordinary academic and clinical teaching (i.e. that opportunity should be given for the discussion of the issues as and when they arise);

3) That didactic teaching of the subject has limited value and that more emphasis should be placed on experientially-based and participatory learning;

4) That so far as possible opportunities should be created for multi-disciplinary and inter-professional discussion of the issues and dilemmas in medical ethics.

The first major opportunity to attempt some innovative teaching along these lines came with the setting up, at the behest of the Medical Faculty, in October 1976 of a one week course for 5 th year MB ChB students on Social and Moral Issues in Health Care. The Edinburgh Medical Group and the Medical Students Council were asked to organise this special teaching week. A series of lectures, symposia and case-conferences were arranged which provided opportunity for the study and discussion of a wide variety of contemporary problems of medical ethics and communication in medicine. The topics covered ranged from such traditional issues as abortion and confidentiality, to care of the terminally ill, transplant surgery and more functionally orientated topics such as communication in hospital and the structure of the NHS. Speakers were drawn from teaching and clinical staff of various departments in the Medical School, local hospitals and establishments for the training of nurses, social workers, other health-care professionals and chaplains. There were fourteen sessions in all with the Wednesday afternoon free. The organising secretary of the joint EMG/MSC committee was one of the EMG Research Fellows.

Although this experimental week has not been repeated (for fiscal reasons) the Medical Faculty subsequently approached the Edinburgh Medical Group with the request that it should include the topics dealt with during the week in the annual EMG programme of lectures and symposia. In addition, the week's general success and popularity with staff and students resulted in invitations to the EMG Research Staff to participate in and arrange ethics teaching in seven different Medical Departments - in Clinical Surgery, Community Medicine, General Practice, Geriatric Medicine, Obstetrics and Gynaecology, Psychiatry and Therapeutics.

The form and extent of participation in these teaching experiments has naturally varied considerably from one department to another, depending 
on the needs and requirements of the subject and the time available. Different groups of students at different stages of their course have been encountered: from Ist year undergraduates in Community Medicine, to $4^{\text {th }}$ year students in Clinical Surgery, 5th year students in Obstetrics and Gynaecology, Psychiatry and General Practice, final phase students in Therapeutics and Geriatric Medicine and post-graduate students in Psychiatry.

In Community Medicine the Research Staff were asked in the first year to give two introductory lectures on medical ethics. In the second year, at the suggestion of the Research Staff, two multidisciplinary case-conferences were held instead. In Clinical Surgery two sessions each year were devoted to the discussion of the management of terminal cancer patients. These took the form of a ' grand round ' with multi-disciplinary participation and a patient being presented on two occasions. The involvement in Obstetrics and Gynaecology and Psychiatry was much more extensive. In the former this took the form of six seminars each term. These were of a voluntary nature and held during the lunch-hour so that midwives, social workers and divinity students could attend. The cases presented and dilemmas discussed covered a wide range of moral issues in reproductive medicine, including contraception, sterilisation and abortion, sexual therapy, artificial insemination, counselling, consent communication and the role of institutions and professions.

In Psychiatry the research staff together with additional resource staff including hospital chaplains and philosophers, were invited to participate in pairs in the clinical tutorials themselves. Each group of students had two such tutorials each term. The cases were deliberately chosen to illustrate moral dilemmas in psychiatry, for example dilemmas over restraining voluntary patients, questions relating to the treatment of alcholism, compulsory hospitalisation and treatment, suicide and parasuicide. More recently the experiment was extended so that the resource staff participated weekly with the same group over the whole term. This had the advantage that the issues could be discussed more naturally when they arose.

Participation in the General Practice course involved one of the research fellows sitting in the tutorials for the whole term and then being invited to contribute a paper at the final tutorial for each term. The involvement with final phase students in Therapeutics and Geriatric Medicine took the form of intimate multi-disciplinary case-conferences which encouraged the frank discussion of many anxiety-producing personal dilemmas. These issues mainly concerned the communication of prognoses, the change of régime in terminal care from a therapeutic to palliative approach, and problems of intervention with elderly patients, particularly the patient with psycho-geriatric problems. One of the research fellows was also asked to participate i special seminars on compulsory hospitalisation an treatment of mental patients in the post-graduate programme in Psychiatry.

All these 'experiments' (which will be reported more fully in due course) have been undertaken and repeated on a trial-and-error basis. The enthusias of staff and students has encouraged discussion in the Medical School of how these experiments might be continued in the future. The long-term future of the programme is uncertain, but so long as the EMG Research Project on Medical Ethics and Educatiof continues the research staff will continue to participate in and help to arrange and co-ordinate these new teaching activities.

I E THOMPSO

Research felloळ

How do nursing students learn about medical ethics?

An attempt to begin to answer this question was made in the course of the work of the EM@ Commission on the Study and Teaching of Medicap Ethics. The intention was to find out from nurse teachers what provisions they consider they make to encourage nursing students to examine morab dilemmas of contemporary health care; and alsọtob discover the views of practising nurses on the question of how nursing students learn abồ medical ethics.

To this end a small-scale investigation was carried out. Firstly, nurse teachers on four generâ nurse training programmes in Edinburgh (two

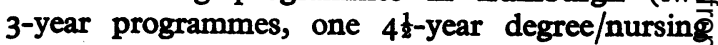
programme and one college-based 3-year diplom? course) were invited to complete a questionnairg form and twenty-one returns were made. Secondlythroughout one local large general hospital, copie $\overline{3}$ of another questionnaire were distributed to trained and trainee nurses; a total of forty-six complete forms was received (about two thirds of the number distributed).

In describing how they consider their students learn about medical ethics, and learn to cope with moral dilemmas in practice, the teachers identified wide variety of influences. These ranged from discussion with peers and teachers to the mass media . ... and from reading to the example of nurses in wards. The provisions made by the teachers themselves varied amongst the four training programmes. One relies mainly on discussion groups while another also involves sessions with the hospitas chaplain, reading and reference to the ICN Code of Ethics; the third programme uses role play, films and TV entensively and the fourth stresses the importance of learning opportunities at various stages of training and in relation to all nursing topics taught. The diploma and degree programmes 
encourage teachers to undertake clinical supervision of students in addition to theoretical teaching and these groups of teachers see this as an important opportunity to discuss moral dilemmas as they are encountered by students in clinical settings.

In their questionnaire the practising nurses were asked to identify what dilemmas they felt arose in their work. Many different moral dilemmas were specified but, interestingly, three particular issues seem to predominate, irrespective of clinical specialty. These are:

I) Issues arising in the care of terminally ill patients (in particular, about the use of sedation).

2) Whether or not to resuscitate particular kinds of patients following cardiac arrest.

3) Whether or not patients and/or relatives should be told the truth about diagnosis (in particular, a diagnosis of cancer and in cases where the doctor wishes to withhold the truth).

Asked about provisions available to help student nurses learn about medical ethics, the practising nurses identified provisions in the ward and tutorial groups, individual personal support as necessary, and Kardex report discussions. A few student nurses said the provisions made are inadequate and claimed that ward sisters tend to avoid discussion of morally controversial issues. Provisions made in the classroom were considered by the student nurses to be helpful, whereas the trained nurses seemed unsure or unappreciative of this contribution. Interestingly, both the student nurses and the trained nurses identified 'experience' and 'example of senior nurses' as the two most important factors contributing to nursing students' learning about medical ethics.

It was felt by the nurse teachers and practising nurses that improved learning opportunities were needed to bring about a more informed and responsible approach to moral decision-making in nursing. Argument was made for more interprofessional debate, better communication between nurses and doctors, and greater emphasis on ethics in the nursing curriculum.

So, even although provisions are made for nursing students to learn about medical ethics, it appears that more planned learning opportunities are needed and wanted. Nurses have always participated in the Edinburgh Medical Group's ordinary extracurricular activities, including lectures, symposia, study days and residential conferences. More recently some innovative and experimental teaching of medical ethics for nurses has been possible through the EMG Research Project. Examples of this are the courses of four half-day 'workshops' on moral issues in health care held in Queen Margaret College in 1977 and 1978 at the invitation of the lecturer in charge of the course which prepares registered nurses to become clinical teachers. Between thirty and forty students were involved in each course, including trainee clinical teachers, district nurses, health visitors and social work students. Each workshop involved a case presentation and smallgroup discussion with some theoretical input by one of the 'resource personnel' taking part (two chaplains and two philosophers). In general the reaction to the course was overwhelmingly favourable and it is hoped that it may be repeated, perhaps involving other health care professionals as well. In addition, planning is under way to involve the EMG Research Fellows in medical ethics teaching in the University's Department of Nursing Studies. These 'experiments' in their own right make a useful contribution to the teaching of medical ethics in nursing education. In addition, they may help to demonstrate that including multi-disciplinary discussion of moral issues in health care within the nursing curriculum may be a realistic proposition rather than just an idealistic dream.

ALISON J TIERNEY Nursing adviser

\section{Teaching and learning of medical ethics in Edinburgh: traditional aspects}

In Edinburgh, the Department of Forensic Medicine has the responsibility of teaching the small body of law and etiquette which is regarded as indispensable to the practice of medicine. That is the most explicit and perhaps the only manifestation in the formal curriculum of the teaching of medical ethics.

In its fullest extent, the teaching and learning of medical ethics is more complex and more diffuse. From the point of view of the teacher, it would seem that medical education is inseparable from medical ethical education (Scratch any teacher of medicine and you will find a teacher of medical ethics) and from the point of view of the student the acquisition of attitudes cannot be separated from the acquisition of knowledge and skills.

Medical education may be seen as a process of passing on a body of factual knowledge, a repertoire of clinical skills and a gradually accumulating apparatus of professional habits, manners and attitudes. The graduate of the medical school is distinguished from the first year entrant not simply because he knows more and can do more, but because he has acquired, if not a high gloss finish, at least a serviceable undercoat of professionalisation.

These three components of medical education, knowledge, skills and attitudes, are not uniformly accessible to study. The transmission of factual knowledge is easiest to consider. One can begin ignorant and end informed. A teacher may help or simply encourage. There is a science, or at least a methodology, of educational assessment which permits achievement to be measured with reasonable numeracy and peace of mind.

The teaching, learning and assessment of skills is less crisply sorted out, but a variety of honest 
attempts are made in the name of Finals, in which humanity combines with breezy simplification and a confidence on the part of the examiners that they know a good student when they see one, to produce an agreed yardstick of clinical competence.

The third factor, the vague but indispensable concomitant of skill and knowledge, is more mysterious both in its being and its transmission. The body of values and attitudes, explicit and implicit and including much of what is widely regarded as medical ethics, is much less susceptible to educational analysis. Professionalisation is a prolonged and subtle indoctrination with the values and habits, the inward and outward hallmarks of a closed group, and for most medical students it is the principal vehicle of ethical learning.

A rigorous study of how medical ethics is learned would prove unrewarding for the educationalist or social scientist. There is not much that can be measured or counted. Investigations must founder on problems of definition of training objectives, description of relevant interactions and the measurement of attainment. The field is therefore open for assertion and speculation, fuelled by presupposition and supplemented, where necessary, by individual observation inevitably restricted by person and circumstance.

Two limited local surveys have been carried out on the teaching and learning of medical ethics in Edinburgh. They are presented not so much to elucidate the matter as to demonstrate the difficulty of its being investigated. The two studies are in a sense complementary, the first being of teachers, represented by their heads of departments, the second being of pre-registration housemen, the vast majority of whom were local graduates and therefore the products of education provided by the former.

Thirty-one of thirty-nine heads of departments answered a preliminary questionnaire. Two thirds of the respondents stated that there was no formal provision for the teaching of medical ethics, but that informal discussion of moral dilemmas took place with undergraduates on a case-related basis as opportunities arose in the course of practical teaching. A similar proportion considered that students acquired education in moral attitudes through education in their subject within their departments. Content of ethical education was determined by specialist interest, and the majority favoured as method the informal, case-related approach alluded to above.

Forty-five of seventy-seven housemen surveyed responded. They were asked in what areas of practice they experienced social, ethical or communication difficulties and how well they had been prepared to deal with them. Problems concerning death, dying, and bereavement figured prominently. Preparation for dealing with them was felt to be inadequate. Views on how this might be remedied were invited. On the whole self-teaching and experience ranked highest, and many responden $\overline{\mathrm{S}}$ felt that nothing in their undergraduate education assisted them with problems encountered in the firs year of practice. There was general scepticism abo formal teaching.

Teachers evidently feel that they are passing attitudes and values. Students, it appears, feel thait they pick them up for themselves. Perhaps both afe right. The Edinburgh curriculum is characterise by long exposure of students in small groups individual teaching clinicians, both senior and juniof. The process of professionalisation is therefore diffuse in time and space, and is in any case by nature so integral to the teaching and learning of medicine as to proceed perhaps without the explicir awareness of teachers and learners. Few generalis? tions are possible and, for the reasons stated, litte analytical work has been done. Perhaps an anthro $\rightarrow$ pological understanding is most appropriate, with the tribe as the model rather than classroom. COLIN CURREE Medical adviser

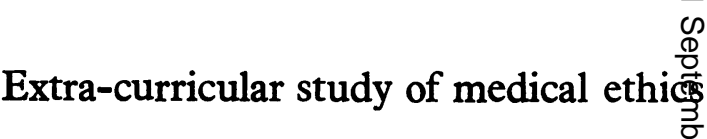
The general aim of the EMG Research Project is develop the study of medical ethics in Edinburgit and, in association with other Medical Groups anj] professional organisations, in other British centres of medical and nursing education. Within this general aim, the project has two major objectives: to exp medical ethics teaching in the medical school conte (discussed in the previous section); and to stufi selected medical ethics topics in appropriate deptR. The latter is being done in multi-profession working groups, by sustained informal interdišciplinary discussion between practitioners, teacherst students and laymen with experience of the relevant topic. Two of these groups, on death and bereave ment and on resource allocation, have completed their work, and it is hoped that their reports will be published in due course. In the meantime working groups on mental health, reproductive medicinge and medical research are also in progress.

The multi-disciplinary working groups themselvę are quite small, each having about twenty members In order to give them a wider sounding board, and also to integrate their work with the project's othef activities, a number of extra-curricular conferencess and seminers were organised. In connection wi the first working group, two residential studere conferences, on 'Death and Professional Ethos' and on 'Professions and Professional Education', we followed by a series of weekly case-conferen discussions on doctor-nurse-patient attitudes, and $: \vec{a}$ half-day conference on 'Convergent and Divergent Elements in the Ethics of Nursing and Medicine? These were held during the autumn and spring terms of the first year of the project (1975-1976\% 
During the summer term and the following autumn, a series of evening seminars on 'Health, Poverty and Scarce Resources', and a residential conference on 'The Ethics of Resource Allocation' discussed the theme of the second working group. In the spring term of the second year (1976-1977) a large two-day conference was organised in association with the Society for the Study of Medical Ethics: this conference, on 'Human Birth', was designed to open up local discussion of the issues to be studied by the fourth working group. In the autumn term of the third year (1977-78) two further residential conferences were held. One, on 'Moral Dilemmas in Psychiatry', along with a series of lunch-time seminars on 'The Meaning of Madness' was planned as a pilot for the third working group. The other, on 'Learning to Communicate', which was preceded by a series of evening case conferences on 'Communication in Health Care', was concerned with issues of common interest to all of the working groups.

Overall, these events involved a considerable number of students from all of the relevant disciplines, ranging from over a hundred at the largest non-residential conference to an average of thirty at residential events and of twelve at small group discussions. The number of teachers and practitioners involved as lecturers and leaders was also large, many different specialities and disciplines being represented. From the working groups' point of view these events were particularly helpful: the proceedings were reported to them and many of the questions raised by the students were later examined by the working groups in greater detail. From the students' point of view, elicited by requests for written comments, these events were considered, with few exceptions, to be helpful learning experiences. The most helpful, in the students' view, were the residential conferences, which are able to achieve a great deal in a short time: case-conference discussions of moral and inter-professional questions were also judged helpful, particularly those in which role-play was used.

The Research Project responsible for the activities described in this and previous sections was funded by the Leverhulme Trust and the Nuffield Provincial Hospitals Trust: and it is based in the University of Edinburgh, the Deans of the Faculties of Medicine and Divinity and the Director of the Nursing Studies Research Unit acting as Grant
Holders. The initiative for the project however came from the Edinburgh Medical Group, which along with the University is responsible for its conduct through the Project Steering Committee on which the student officers of EMG serve. Student initiative and involvement thus play an important part in the project, and without the existence of EMG's continuing student constitutency, it is difficult to see how a programme of the kind described here could have been set up so easily and carried out so successfully. All the activities described, it should be added, were arranged in addition to the annual series of lectures, symposia, and discussions arranged by the EMG students and senior advisers.

At this stage in the project any conclusions must be provisional. But support and enthusiasm for these curriculum-related and extra-curricular activities suggests that they met a widely felt need for study and discussion of medical ethics topics in the medical school context. A similar conclusion also seems to be emerging from the project's involvement with nursing education. For theoretical and practical reasons alike, such study should be multi-disciplinary and dialectical (i.e. allowing for the exchange and discussion of different points of view) and its content should be related to concrete cases and clinical experience. In practice this suggests a multiple strategy approach to medical ethics teaching and learning, including both curriculum-related and extra-curricular activities, with some room for consideration of ethical, legal and other theories as a framework for the substantial debate about cases and examples. The conclusion forced on the EMG research staff by their experience during the past three years is that such a multiple strategy approach will probably be needed in the foreseeable future, just as it has proved necessary during the period of the teaching experiments.

K. M. BOYD

Research fellow

\section{Acknowledgements}

The Edinburgh Medical Group Research Project in Medical Ethics and Education gratefully acknowledges financial assistance from both the Leverhulme Trust Fund and the Nuffield Provincial Hospital Fund. 